\title{
The Impact of the First Wave of the COVID-19 Pandemic on Parents of Children with Externalising Difficulties in Ireland: A Longitudinal Cohort Study
}

\author{
Anna Berry ${ }^{1}$, Tom Burke ${ }^{1}$, and Alan Carr $^{1}$ \\ ${ }^{1}$ University College Dublin
}

May 5, 2021

\begin{abstract}
Background: This longitudinal cohort study aimed to examine the impact of the first wave of the COVID-19 pandemic in Ireland on parents of children with externalising difficulties, in comparison to parents of children without such difficulties. Method: Parents of 159 children completed online self-report measures at three time points during the first wave of the COVID-19 pandemic; 1) Delay and Mitigation Phase (March 2020 - May 2020), 2) Reopening of Society Phase (June 2020 - July 2020), and 3) Wave 2 Case Acceleration Phase (September 2020 - October 2020). Participants were allocated to the Clinical group if they met the clinical cut off point on the Conduct or Hyperactivity/Inattention subscales of the Strengths and Difficulties Questionnaire at Time 1. Results: Parents of children with externalising difficulties experienced significantly higher levels of stress, lower levels of wellbeing, and engaged in higher levels of avoidant-focused coping strategies longitudinally. There was a significant difference between outcomes at the different phases of the COVID-19 pandemic, for stress related to parenting, personal/family stress related to the impact of the COVID-19, and type of coping strategies employed. Children with externalising difficulties, in comparison to children without externalising difficulties, showed significantly greater adjustment over time for behavioural and emotional difficulties. Conclusions: Results provide important information regarding the trajectory of psychological outcomes in parents of children with externalising difficulties over the first wave of the COVID-19 pandemic, highlighting the need for increased parental supports during, and after, the COVID-19 pandemic.
\end{abstract}

\section{Hosted file}

Main_Text_File.pdf available at https://authorea.com/users/412075/articles/520881-the-impactof-the-first-wave-of-the-covid-19-pandemic-on-parents-of-children-with-externalisingdifficulties-in-ireland-a-longitudinal-cohort-study

\section{Hosted file}

Tables.pdf available at https://authorea.com/users/412075/articles/520881-the-impact-ofthe-first-wave-of-the-covid-19-pandemic-on-parents-of-children-with-externalisingdifficulties-in-ireland-a-longitudinal-cohort-study

\section{Hosted file}

Figures.pdf available at https://authorea.com/users/412075/articles/520881-the-impactof-the-first-wave-of-the-covid-19-pandemic-on-parents-of-children-with-externalisingdifficulties-in-ireland-a-longitudinal-cohort-study 